June 1991

\title{
Psychiatric Consultation for the Demented Elderly
}

Kenneth Paul Rosenberg, M.D.

Cornell University Medical Center, New York Hospital, New York

Follow this and additional works at: https://jdc.jefferson.edu/jeffjpsychiatry

Part of the Psychiatry Commons

Let us know how access to this document benefits you

\section{Recommended Citation}

Rosenberg, M.D., Kenneth Paul (1991) "Psychiatric Consultation for the Demented Elderly," Jefferson Journal of Psychiatry. Vol. 9 : Iss. 2 , Article 7.

DOI: https://doi.org/10.29046/JJP.009.2.004

Available at: https://jdc.jefferson.edu/jeffjpsychiatry/vol9/iss2/7

This Article is brought to you for free and open access by the Jefferson Digital Commons. The Jefferson Digital Commons is a service of Thomas Jefferson University's Center for Teaching and Learning (CTL). The Commons is a showcase for Jefferson books and journals, peer-reviewed scholarly publications, unique historical collections from the University archives, and teaching tools. The Jefferson Digital Commons allows researchers and interested readers anywhere in the world to learn about and keep up to date with Jefferson scholarship. This article has been accepted for inclusion in Jefferson Journal of Psychiatry by an authorized administrator of the Jefferson Digital Commons. For more information, please contact: JeffersonDigitalCommons@jefferson.edu. 


\title{
Psychiatric Consultation for the Demented Elderly
}

\author{
Kenneth Paul Rosenberg, M.D.
}

\begin{abstract}
Psychiatric consultations for the demented elderly are often required and requested by the medical service. With the rise in the number of demented elderly being housed in acute care hospitals, the need for these consultations is increasing. In this paper, the author presents a case and discusses the role of the consultant in (1) diagnostics, (2) therapeutics, (3) assessment of involuntary vs. voluntary placement in an institution, (4) medical staff education, (5) family education, and (6) the management of evoked feelings and countertransference among the medical and nursing staff.
\end{abstract}

\section{INTRODUCTION}

In the past decade, an increasing number of elderly demented individuals have been temporarily housed in general hospitals while awaiting placement in skilled nursing facilities $(1,2)$. An early study found that on a given day in the state of Massachusetts, 823 elderly patients who did not need hospitalization were occupying acute care beds while awaiting placement (3). These elderly patients have been appropriately labeled "the boat people of the health care delivery system"; this is particularly true of the demented elderly with behavioral disturbances who are considered undesirable by the hospitals and nursing homes. With the predicted "graying" $(4,5)$ of American society and an anticipated shortage of nursing home beds (6), we can anticipate further increases in the number of demented elderly in acute care hospitals.

The increase in the number of demented patients is related to the projected increase in life expectancy; dementia is more likely among the older elderly, occurring in $2.8 \%$ of those between the ages of 65 and 74 and $28 \%$ of those at age 85 or older (7). Schneider and Guralnik (7) predict that by the year 2040, between 6.1 and 9.8 million Americans will have a moderate-to-severe dementia, an increase of at least 3.7 million from 1985. These authors note that the fiscal costs of housing and caring for these patients will be considerable, easily approaching the amount of the current federal deficit $(7,8)$.

Psychiatrists who provide consultation in general hospitals are commonly called upon to evaluate these patients, and to offer diagnostic, treatment, and placement recommendations. In the first year of the geropsychiatric consultation service at the

Assistance provided by Kenneth Tardiff, M.D., Herbert J. Schlesinger, Ph.D., George Reader, M.D. and Geanne Perlman Rosenberg, J.D. 
Royal Liverpool Hospital, the majority of referrals were for demented patients (9). Reviewing referrals to psychiatrists in a skilled nursing home setting, Bienfield and Wheeler (10) found that $51 \%$ of the patients had a dementia. Among general medical in-patients who are elderly, $45 \%$ suffer from depression and require psychiatric consultation $(11,12)$. In general, the utility of psychiatry consultations for patients and medical staff has been well-documented $(1,10,11,13,14,15)$. In addition, psychiatric consultations are cost-effective, reducing the length of medical and surgical hospitalizations $(16,17)$ and reducing total hospital expenditures per patient (18).

\section{CLINICAL EXAMPLE}

The following clinical example presents an elderly demented patient who was referred to the consultation-liaison psychiatry service at a major teaching hospital. Largely because of difficulty placing this patient in a nursing home or institution, she was hospitalized for 275 days. Had it not been for the waiting period to transfer her to a long-term placement, her hospitalization would have only lasted for a few days.

This 74 year old woman was brought to the emergency room from a nearby shelter for the homeless where she had been living for two months. Her presenting complaints were bilateral foot swelling, pain, and erythema. Upon examination, she was noted to have profound memory impairments. She recalled little more than her own name, and could not recollect the names of her family members. Upon mental status examination, she was disoriented, confused, and had impairment of shortterm and long-term memory. Her attention and rudimentary language skills were intact. There were no other neurological findings. She was admitted to the medical service for evaluation and treatment of dementia and cellulitis. By day three, all medical tests were completed. Treatable causes of dementia (i.e., hydrocephalus, thyroid disturbances) were ruled out, and her cellulitis improved with conservative medical care. Her discharge diagnoses were arterial insufficiency and dementia of unknown etiology.

On day four, the medical service planned to discharge her back to the shelter, but the social worker protested saying that the patient seemed to be too cognitively impaired to leave the hospital. To settle the matter, a psychiatry consultation was requested. The consultant noted her deficits in memory, language, visual-spatial comprehension, judgement, and insight, obtained a history from the patient suggestive of past alcohol use, and offered a presumptive diagnosis of alcoholic dementia. The consultant agreed with the social worker that the patient could not function independently, required more supervision than the shelter provided, conceivably posed a danger to herself as a result of her severe dementia, and would be best cared for in a skilled nursing home.

The consultant added that she wandered easily, experienced diurnal confusion (i.e., "sun-downing"), and was distractable, delusional, and paranoid. A small dose of a high-potency neuroleptic (haloperidol, $0.5-1 \mathrm{mg}$. p.o.) was advised, to be given early in the evening when she became more confused. For extrapyramidal side effects, a small dose of an antiparkinsonism medication (benztropine mesylate, 1-2 mgs. p.o. 
prn) was advised. The consultant suggested that these medications be given initially as needed, and then on a once-to-three times a day basis. In addition, the staff was educated about the utility of prescribing benzodiazepines. For extreme agitation, restlessness, wandering, and anxiety, a low-dose of a short-acting benzodiazepine (lorazepam, 0.5-1 mgs. po/im prn) was advised. Staff was advised against putting the patient on standing doses of benzodiazepines, to avoid the development of tolerance and over-sedation. (The use of psychotropics in the elderly will be briefly reviewed in the discussion).

Psychiatrists from the consultation-liaison service spent a considerable amount of time educating the medical staff about dementia in an attempt to stir academic interest in the patient. The consultant also assisted staff in ironing out disputes over whether or not the patient should be discharged, and "whose fault" it was that this patient was being housed on the medical service while awaiting transfer.

As the hospitalization progressed, the patient became more disoriented and disorganized, drinking blood and urine cultures which she believed to be cocktails (i.e., "a bloody Mary"). Late one night, she wandered outside the ward, into the hospital lobby and nearly outside the confines of the hospital. At this point, lorazepam were regularly prescribed, haloperidol were increased ( $1 \mathrm{mg}$. at bedtime), and a posey restraint vest was used to prevent the patient from wandering off of the ward. Although her psychosis was refractory to medication, she was marked less agitated with the increased dosings.

Having failed to place the patient in several nursing homes, partly for financial reasons, placement at a local state psychiatric hospital was tried. She was denied placement at the state facility because she was deemed not to have a severe enough psychiatric disturbance. According to the reviewer from the state hospital, patients with refractory illnesses such as severe manic-depression or chronic schizophrenia were more suitable for their placement. The state hospital reviewer advised attempting placement in a nursing home, and trying other pharmacological approaches.

On two separate occasions, the patient was accepted by nursing homes and transferred. Yet the nursing homes found her too disruptive and disturbed; she was promptly returned back to the hospital. Additional pharmacological measures were tried independently with minimal success. The haloperidol was raised ( $2 \mathrm{mgs}$. several times a day), benztropine was raised ( 2 mgs. twice a day), and lorazepam were raised ( $1 \mathrm{mg}$. several times a day). With these changes, the patients experienced more side effects and little benefit. With the increase in neuroleptics, she developed severe tremor; with increased antiparkinsonism medications, she became increasingly confused; and, with increases in the benzodiazepines, she became ataxic and increasingly confused. For a brief time, lithium was tried with no decrease in confusion and agitation.

Given the inability to transfer the patient to a nursing home, the social worker re-applied to the state hospital. The social worker explained that it had been about six months since we originally applied. In the interim, we had followed the suggestions of the state hospital reviewer, but the patient had failed our medication trials and failed two placements. Sensing the desperation of the situation and the inability 
of the patient to improve, the state hospital re-considered the application and agreed to accept the patient.

During our negotiations with the state hospital, two of the patient's relatives were located through the local Bureau for Missing Persons. The patient's nieces opposed the proposed transfer to the state hospital, and urged the medical staff to "treat" her and restore her functioning. After a meeting with the psychiatric consultant, the family understood that the patient was not likely to improve, nor would she be able to return to the community. On day 275 , the patient was transferred to the state psychiatric facility.

\section{DISCUSSION}

The psychiatric consultant has an important role to play in assisting the medical staff with caring for demented patients who are awaiting transfer. Not only must consultants offer diagnostic and management recommendations, but they must guide families, patients, and staff as they work towards institutionalization. Patients and their families are often reluctant to acknowledge the need for nursing home placement (19) and generally require education, guidance, and counseling. When patients refuse institutionalization, the psychiatrist needs to assist staff in determining whether involuntary placement should be pursued, based on the danger that the demented patient poses to himself or others.

Psychiatric consultants are frequently asked to recommend medications that can be used to manage these patients. Medicating the demented patient is particularly challenging. Young and Meyers have noted (20) the age-related changes in the absorption, metabolism, distribution, and excretion of psychiatric medications, in addition to age-associated changes in the peripheral and central neurotransmitter systems in the elderly.

The patient presented here required neuroleptics and benzodiazepines. The initial treatment of choice was a low dose of a high-potency neuroleptic (which was less likely to cause falls and increase confusion than a low-potency neuroleptic.) For sedation, a short-acting benzodiazepine was used in judicious amounts. Sunderland and Silver (21) have suggested that neuroleptics are extremely useful in the management of behavioral disturbances and/or psychosis associated with the organic mental disorders. Reviewing several studies, Young and Meyers (20) conclude that neuroleptics are superior to placebo in controlling agitation and psychosis, while there is no evidence for the superiority of one neuroleptic over another. High-potency neuroleptics with greater dopamine-2-receptor blocking action pose a greater risk of extrapyramidal symptoms, especially in the elderly (22). On the other hand, lowpotency neuroleptics with greater anticholinergic, antihistaminic, and alpha-1adrenergic actions, pose risks for sedation, confusion, and orthostatic hypotension (20). In general, older patients receiving neuroleptics are are increased risk for falls and related morbidity and must be monitored carefully.

Benzodiazepines like lorazepam have also been shown to decrease wandering, reduce agitation, and decease restlessness in the demented elderly (20). Lorazepam 
is preferable to many other benzodiazepines because it has a short-half life and lacks long-acting metabolites which may lead to drug accumulation (23). Also, in comparison to many other benzodiazepines, the metabolism and excretion of lorazepam is less dependent on age-related liver deterioration (23). Nonetheless, benzodiazepines have a limited role in the treatment of the demented patients. They may worsen cognitive functioning, increase the risk for falls, and are associated with paradoxical reactions and disinhibition (20).

This clinical example also demonstrates the evoked feelings and countransference that are typical for house officers. The psychiatric consultant is uniquely qualified to help the medical personnel recognize and correct their negative feelings, and arbitrate arguments that arise between social workers, nurses, and house officers.

In this case, we observe the difficulties of housing chronic dementia patients on an acute medical service. As Billing and Leibenluft (24) have discussed, the demented elderly require a special array of medical, nursing, and health care services which are distinctly different from what is provided on most general medicine or psychiatric wards. Doctors must be familiar with prescribing psychotropic medications to the frail elderly; nurses and aides need to know how to assist these patients with the activities of daily living; social workers must be aware of the networks of agencies and institutions that serve this population; and, recreational therapists need to recognize their increased need for physical and mental stimulation. Even the architecture of the ward must be different. The wards must be constructed as safe places for the elderly demented, with locked entrance and exit doors to prevent wandering, elopement, and accidents. While the consultant should be aware of the optimal environment for these patients, he or she must be prepared to help staff manage these patients in the typically sub-optimal acute medical ward.

Finding placement for demented patients with behavioral disturbances is especially difficult (25). The consultant needs to recognize that the ward needs to adjust to the problems that arise with these patients given that they are housed on the service for lengthy periods of time. The psychiatrist needs to educate the medical staff about appropriate placement. For instance, in this case, the staff urged the medical center to transfer the patient to a nearby acute psychiatric hospital. They were surprised to learn that most acute psychiatric hospitals are ill-suited for these patients. Moreover, acute hospitals are reluctant to accept patients who are difficult to discharge.

While a lengthy discourse on the financial factors responsible for the current delays in hospital-to-nursing home transfers is beyond the scope of this report, we should mention some of the reasons why this predicament exists. Placement is much more difficult since the days of psychiatric deinstitutionalization $(1,26,27)$. In the past, state hospitals played a pivotal role in long-term care of the demented elderly (28), while today's state psychiatric hospitals are mainly geared for acute care. Fortunately, our own local state hospital was willing to accept the above-stated patient after she had failed other placements. Nursing homes, on the other hand, are quite selective as to which patients they will admit. Faced with reductions in 
government financing, they have tried to cut costs by accepting fewer psychiatric, severely impaired, or impoverished patients (2). Thirdly, the hospitals that house patients are under tremendous pressure to discharge these patients as soon as possible, before DRG payments are exceeded (29). (This patient's hospitalization was estimated at $\$ 104,146$, although the hospital only collected a fraction of that amount). Clearly, we must do our utmost to insure that the medical care delivery system is modified in such a manner as to better serve our demented patients. Yet, while these patients remain housed in medical hospitals, psychiatric consultation can be extremely useful to the patients, their families, and the staff.

\section{REFERENCES}

1. Campion EW, Bang A, May MI: Why acute-care hospitals must undertake long term care. New England Journal of Medicine 308:71-75, 1983

2. Welch, WP, Dubay, LC: The impact of administratively necessary days on hospital costs. Medical Care 27(12):1117-1132, 1989

3. Administrative day survey. Boston: Massachusetts Hospital Association, 1982

4. Guralnik JM, Yanagishita M, Schneider EL: Projecting the older population of the United States: lessons from the past and prospects for the future. Milbank Quarterly 66:283-308, 1988

5. Spencer G: Projections of the Population of the United States by Age, Sex, and Race: 1988 to 2080. Washington, D.C.: US Bureau of the Census. Current Population Reports. Series P-25. No. 1018. 1989

6. Tresch DD, Duthie EH, Newton M, Bodin B: Coping with diagnosis related groups-the changing role of the nursing home. Archives of Internal Medicine 148:1393-1396, 1988

7. Schneider EL, Guralnik JM: The aging of America-the impact on health care costs. Journal of the American Medical Association: Vol. 263 (No. 17): 2335-2340, 1990

8. Historical Tables: Budget of the US Government: Fiscal Year 1989. Washington, D.C.: Executive Office of the President, Office of Management and Budget; 1989

9. Anderson DN, Philpott RM, Wilson KC: Psychogeriatric liaison referrals (letter.) British Journal of Psychiatry 153:413, 1988

10. Bienenfeld D, Wheeler BG: Psychiatric services to nursing homes: a liaison model. Hospital and Community Psychiatry 40(8):793-4, 1988

11. Kitchell MA, Barnes RF, Veith R, Okimoto JT, Raskind MA: Screening for depression in hospitalized geriatric medical patients. Journal of the American Geriatrics Society 30: 1747,1982

12. Magni G, DeLeo D, Schifanno F: Depression in geriatric and adult medical inpatients. Journal of Clinical Psychology 41:337, 1985

13. Fulop G, Strain JJ, Fahs MC, Hammer JS, Lyons JS: Medical Disorders associated with psychiatric comorbidity and prolonged hospital stay. Hospital and Community Psychiatry 40(1):80-2, 1989

14. Thienhaus OJ, Rowe C, Woellert P, Hilland JR: Geropyschiatric emergency services: utilization and outcome predictors. Hospital and Community Psychiatry 39(12):1301-5, 1988

15. Patterson C, Le Clair JK, Acute decompensation in dementia: recognition and management. Geriatrics 44(8):20-6, 31-2, 1989 
16. Fulop G, Strain JJ, Vita J, Lyons JS, Hammer JS: Impact of psychiatric comorbidity on length of hospital stay for medical/surgical patients: a preliminary report. American Journal of Psychiatry 144(7):878-82, 1987

17. Ackerman AD, Lyons JS, Hammer JS, Larson DB: The impact of coexisting depression and timing of psychiatric consultation on medical patient's length of stay. Hospital and Community Psychiatry. 39(2):173-6, 1988

18. Strain JJ: Cost Offset: Psychiatric intervention in surgery, in New Research Program and Abstracts, page 296. American Psychiatric Association, Washington, D.C., 1990

19. Rosenberg KP, Neuwald R: An Alzheimer's Story (videotape). Filmakers Library Inc., New York City, 1985

20. Young RC, Meyers BS: Psychopharmacology, in Comprehensive Review of Geriatric Psychiatry. Edited by Sadovoy J, Lazarus LW, Jarvik LF, Washington, D.C., American Psychiatric Press, Inc., 1991

21. Sunderland T, Silver MA: Neuroleptics in the treatment of dementia. International Journal Geriatric Psychiatry 3:79-88, 1988

22. Salzman G, Shader RI, Pearlman M: Psychopharmacology and the elderly in Psychotropic Drug Side Effects. Edited by Shader RI, DiMascio A. Baltimore, MD, Williams and Witkins, 1970

23. Harvey SC: Hypnotics and sedatives, in Goodman and Gilman's The Pharmacological Basis of Therapeutics, Seventh Edition, Edited by Gilman AG, Goodman LS, Rall TW, Murad F, New York, Macmillan Publishing Company, 1985

24. Billing N, Leibenluft E: Special considerations in integrating elderly patients into a general hospital psychiatric unit. Hospital and Community Psychiatry 38(3):277-80, 1987

25. Biegelow DA, Cutler DL, Moore LJ, McComb P, Leung P: Characteristics of state hospital patients who are hard to place, Hospital and Community Psychiatry 39(2):181-185, 1988

26. Wasow M: The need for asylum for the chronically mentally ill. Schizophrenia Bulletin 12:129-140, 1986

27. Lamb HR: Deinstitutionalization and the homeless mentally ill. Hospital and Community Psychiatry 35:899-907, 1984

28. Grob GN: The inner world of American psychiatry, 1890-1940: selected correspondence, New Brunswick, New Jersey: Rutgers University Press, 1985

29. Goldstein JM, Bassuk EL, Holland SK, Zimmer D, Identifying catastrophic cases, Medical Care, Vol 26, No. 8:790-799, August 1988 